\section{EL NUEVO CENTRO PARROQUIAL DE SAN JOSE DE CAMPOBASSO/ITALIA}

\author{
Enrico Mandolesi, \\ Arquitecto
}

$148-163$

\section{SINOPSIS}

El conjunto parroquial de San José de Campobasso está constituido, fundamentalmente, por dos cuerpos diferenciados de dos plantas cada uno. El principal de ellos alberga la iglesia $y$, debajo de ella, una cripta destinada a distintas actividades. El otro cuerpo, adosado al principal por un lateral, distribuye la sacristía, el alojamiento del párroco, oficinas y locales de uso diverso. De menor importancia en volumen, y también prácticamente adosados al cuerpo principal, se encuentran el batisterio y el campanario.

En su realización es de destacar, por una parte, la adecuada iluminación natural, que busca el sentido religioso del espacio y, por otra, el contraste entre los tratamientos interior y exterior de la construcción.

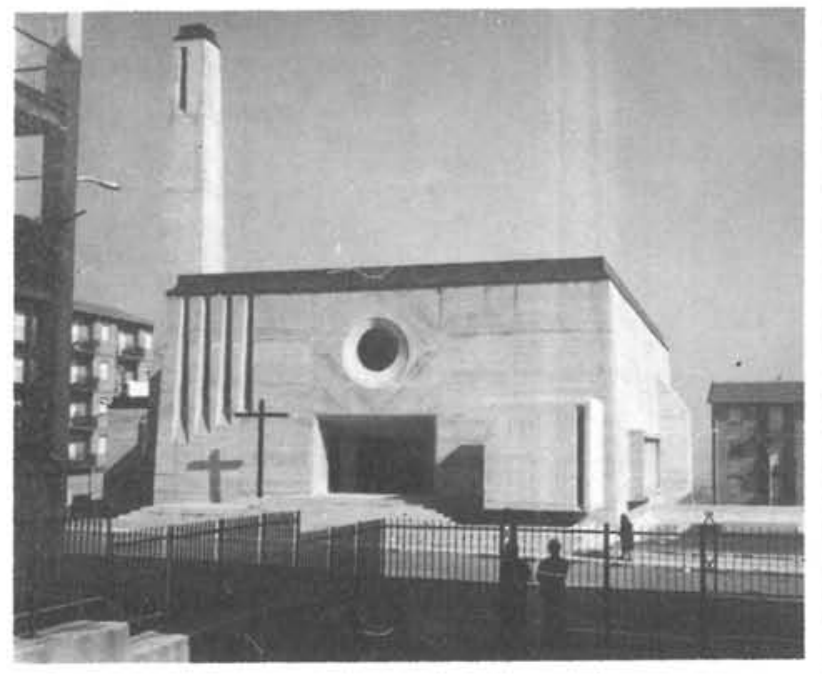

La Iglesia de San José, situada en una plaza de fuerte pendiente constituye, junto con el mercado cubierto, uno de los polos de servicio y reunión de la vida comunal en el barrio Cep de Campobasso.

El edificio consta de dos cuerpos principales: la iglesia y la casa parroquial, aparte del batisterio y el campanario.

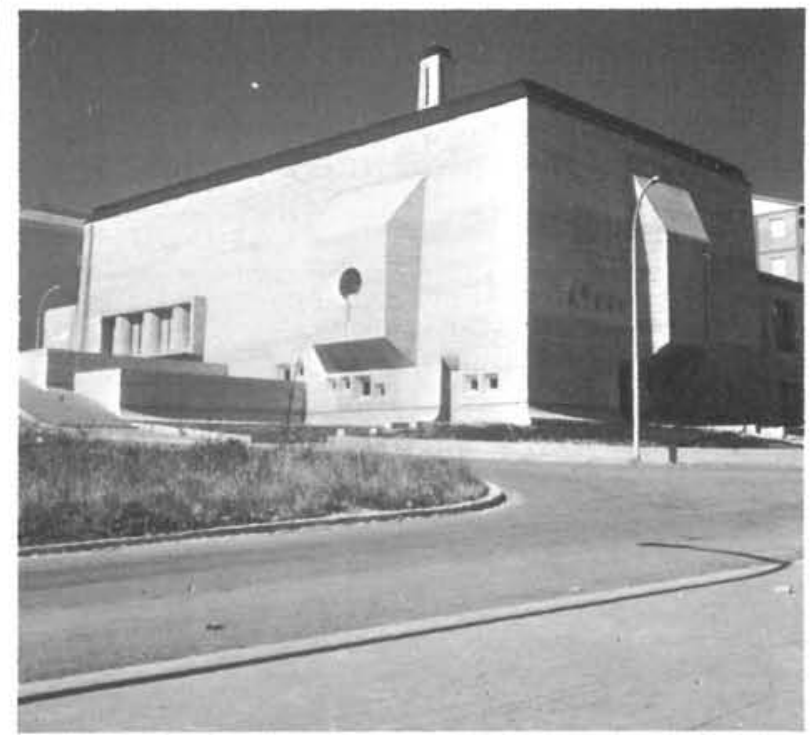

La iglesia se estructura en dos plantas: la superior, a ras de la calle principal, destinada al rito, y la inferior, en semisótano por el declive del terreno, a actividades recreativas. El edificio ha sido concebido como un contenedor compacto de hormigón armado del que destacan las formas derivadas de los actos rituales tales como la entrada, la zona del campanario, el ábside o el espacio ocupado por el altar con el Santisimo; mientras que la zona de servicio del semisótano se adivina por los pequeños huecos dispuestos a intervalos aparentemente irregulares.

En contraposición con el volumen macizo exterior, que parece emerger del suelo al que se une con formas curvilineas, el espacio interno de la iglesia es de configuración abierta. Consta de tres seudonaves que forman de hecho un espacio único, pero que se diferencian formalmente del esquema tradicional por cuanto la cubierta se separa de los muros y está cortada en el centro, formando lineas continuas de luz. Esta iluminación cenital 


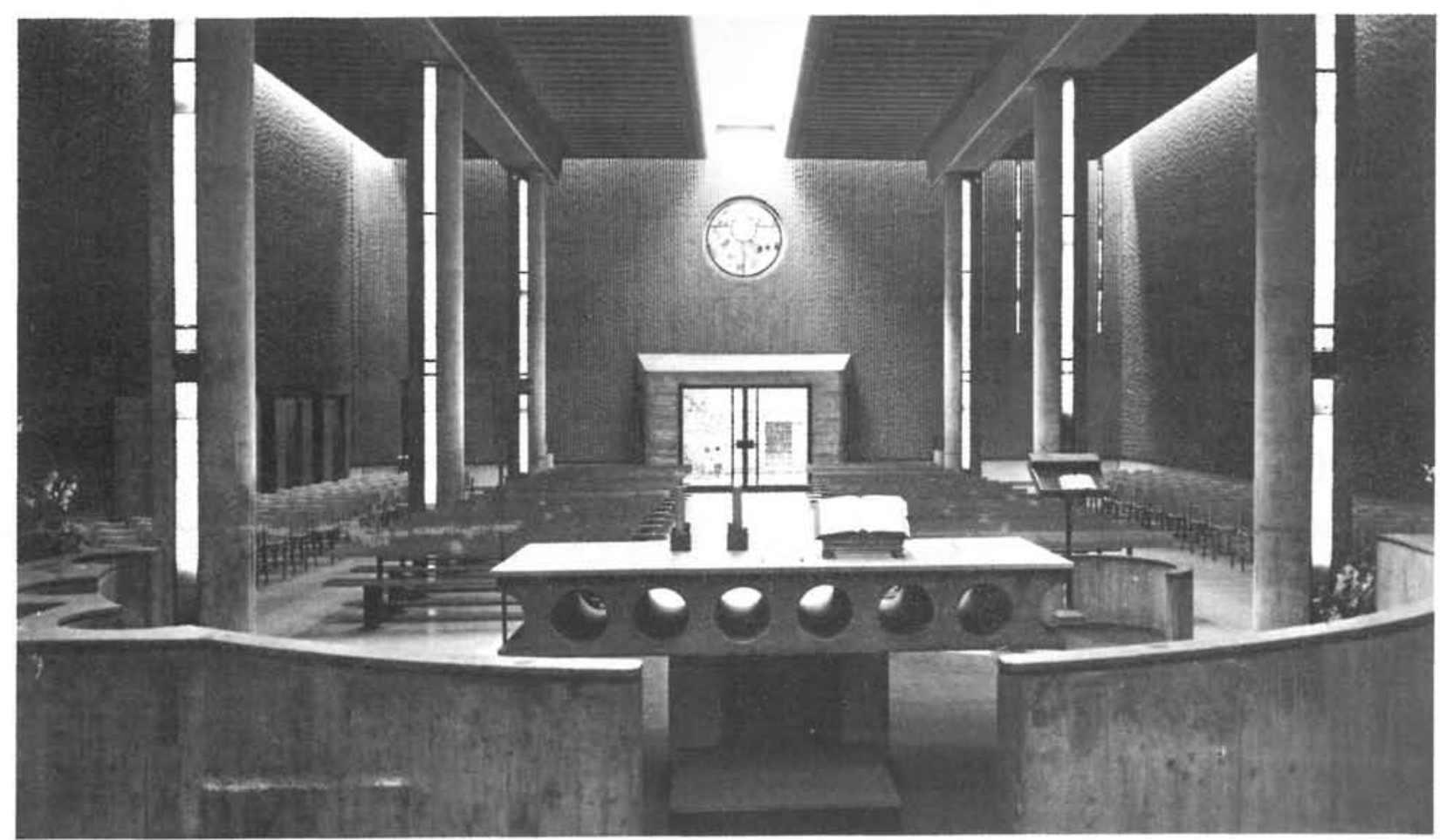

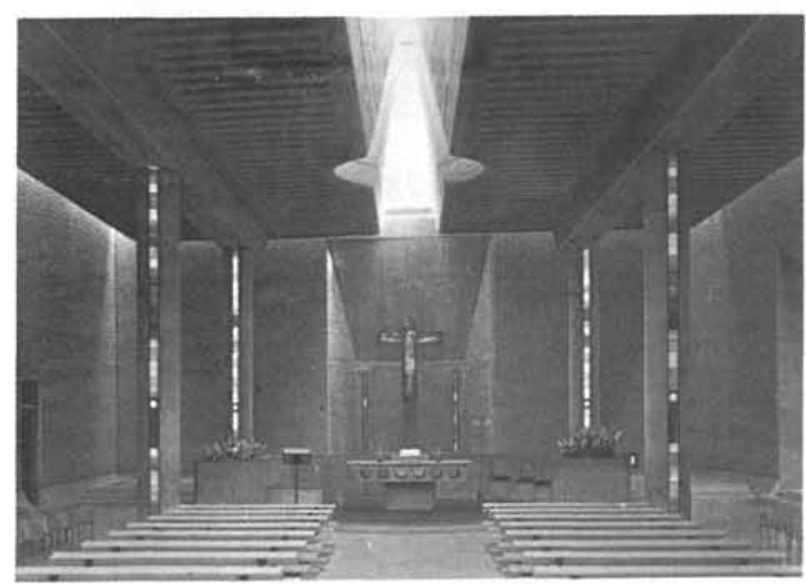

tiene un valor y un significado determinante, ya que confiere al espacio una dimensión metafísica. Además establece un gran contraste entre los muros cerrados continuos y la cubierta, marcado por profundas hendiduras transparentes abiertas hacia el cielo. La hendidura central indica el recorrido real y espiritual hacia el altar mayor sobre el cual se abre, en forma cónica, en una cúpula transparente que ilumina concentradamente el área del oficiante.

Estos efectos luminosos se obtienen gracias a los huecos longitudinales creados por las separaciones entre muros y forjados. Estos, de tipo nervado y labrados, apoyan sobre vigas continuas colocadas sobre una fila de cuatro pilares. Las hendiduras resultantes se cubrieron con material plástico transparente.
En contraposición, las lineas abiertas en las paredes, el rosetón, el crucifijo y los puntos de luz artificial, son objetos translúcidos de colores intensos y difuminados del azul al verde; constituyen casi un contraste negativo en un ambiente de gran luminosidad.

El batisterio es un pequeño espacio cúbico que destaca en la plaza, accesible desde la iglesia, aunque físicamente esté separado de ella.

El campanario, que debía actuar como enlace entre la iglesia y la casa parroquial, además de ser punto de referencia respecto al eje del principal

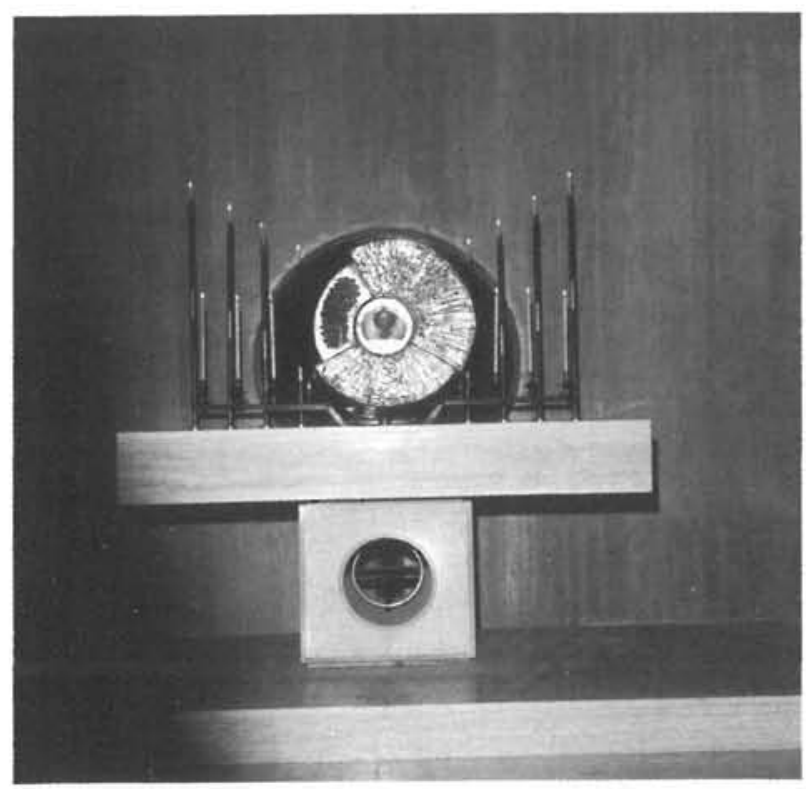




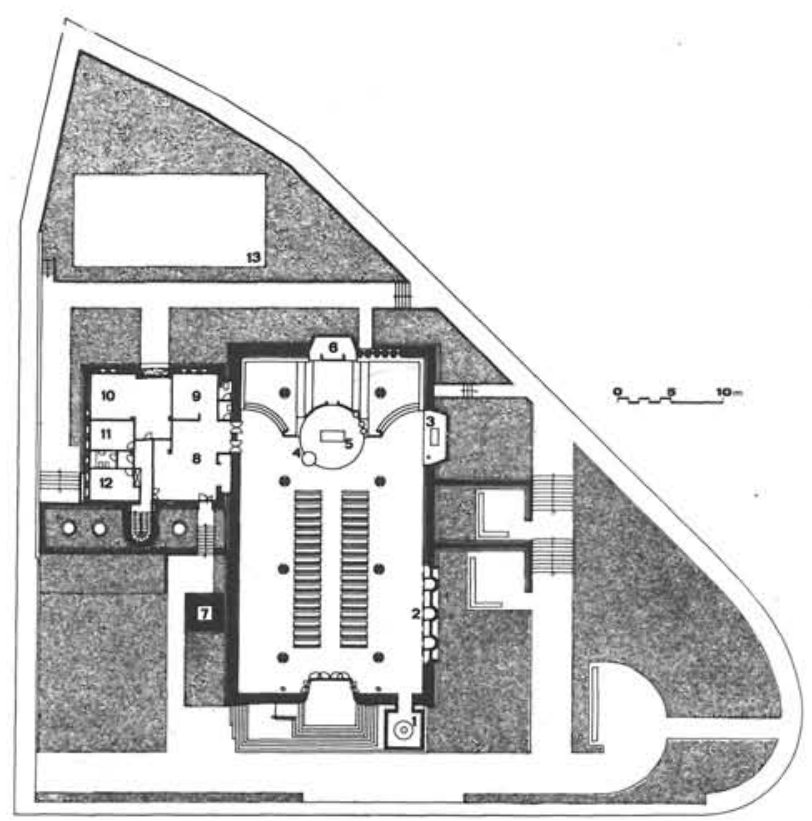

Planta (nivel superior). 1.-Batisterio. 2.-Confesionario. 3.-Santisimo. 4.-Ambón. 5. - Altar mayor. 6. -Coro. 7.-Campanil. 8. - Sacristía. 9. Oficio párroco. 10.-Comedor-estar. 11.-Cocina. 12.-Dormitorio 13. - Juegos.

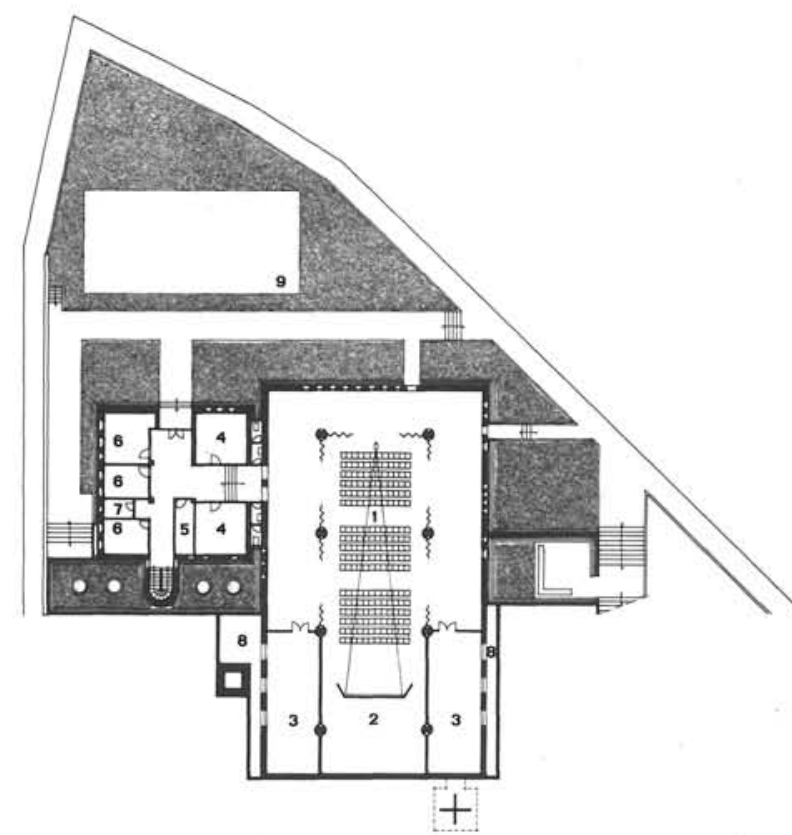

Planta (nivel inferior). 1. - Sala de reunión y proyecciones. 2.-Almacén de sillas. 3. - Juegos y reuniones. 4. - Aula. 5.-Archivo. 6. -Oficio parroquial. 7. - Baño. 8. -lluminación natural. 9. - Juegos.

recorrido peatonal del barrio, asume el papel de soporte de los aparatos de sonido y de señalización.

La casa parroquial, en su papel de elemento secundario, se apoya formal y funcionalmente en la iglesia. El uso del hormigón armado, dejado visto en su interior, refleja la adecuación entre la técnica constructiva y la intencionalidad y finalidad del proyecto. Al igual que la iglesia, consta de dos plantas: la superior, al nivel de la calle, la ocupan

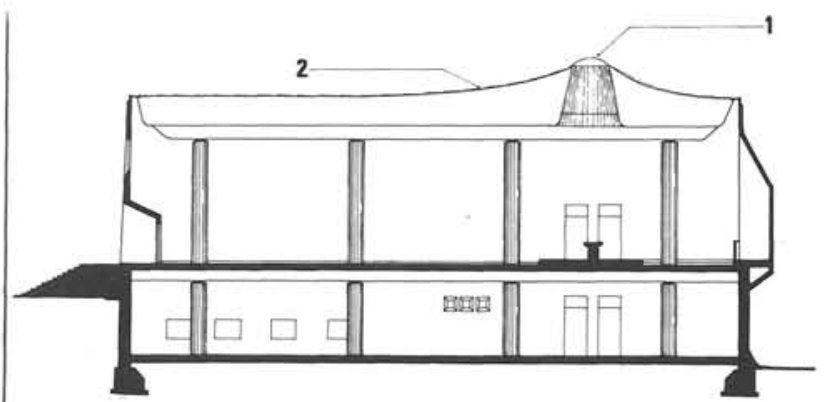

Sección longitudinal.

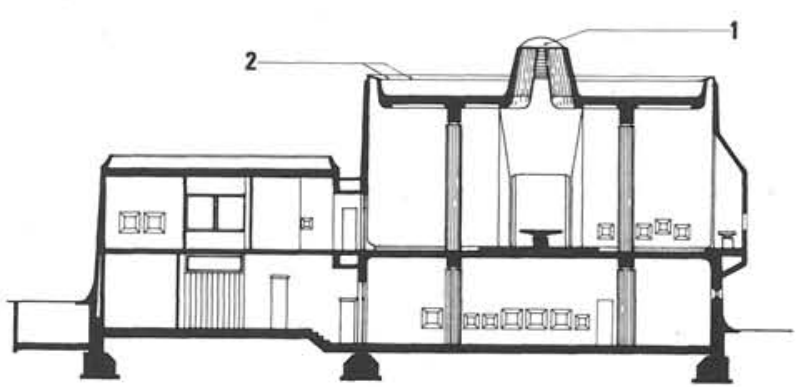

Sección transversal. 1. - Claraboya. 2. -lluminación en "perspex».
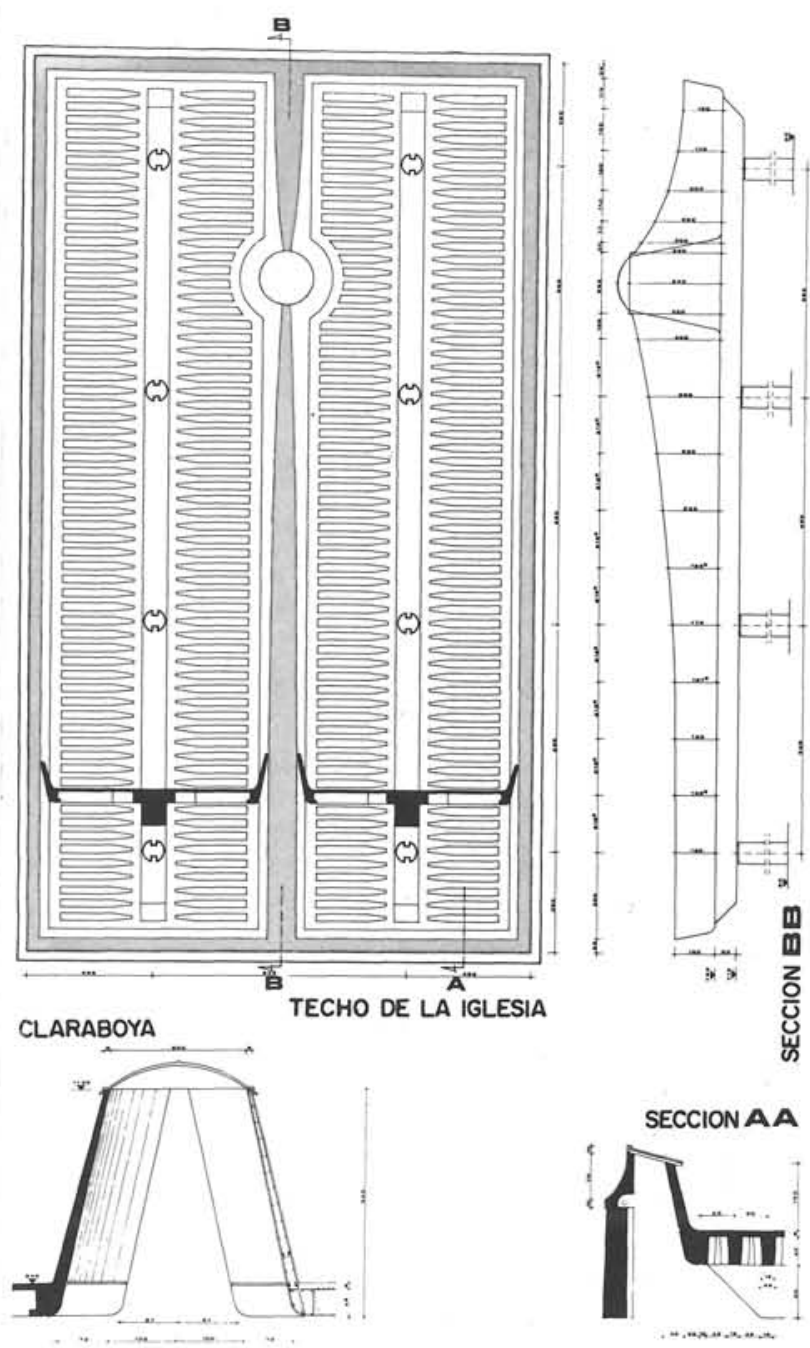


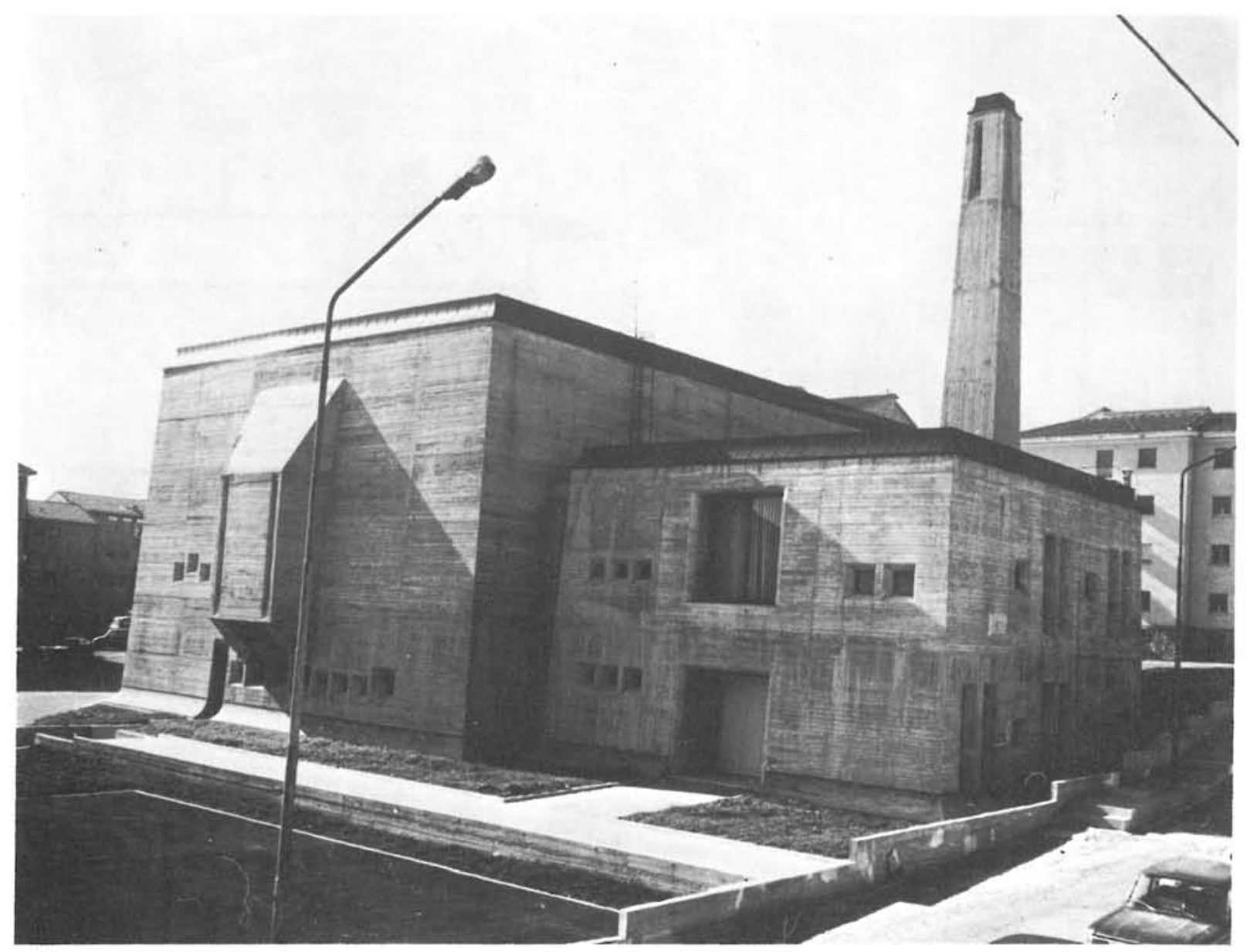

la sacristia y el alojamiento del párroco; la inferior alberga las oficinas parroquiales y una serie de dependencias de uso diverso.

En la construcción se intentó unificar el proceso de elaboración $y$, para ello, por un lado se ha empleado un único material: el hormigón armado; $\mathrm{y}$, por otro, se ha unificado al máximo el número de encofrados distintos. Así, mientras que las fachadas exteriores se han realizado con encofrados tradicionales de madera de abeto cepillada, en la parte interior de los muros se han empleado encofrados metálicos laminados en forma de greca, y para los pilares de la iglesia, dos únicos encofrados de lámina reforzada de acero. Por su parte los forjados nervados se prefabricaron a pie de obra y con un número muy limitado de moldes.

El acabado de los muros en el interior de la iglesia es de "grecas quebradas", obtenidas con la martellina sobre la superficie regular formada por los moldes laminados.

Los muros de la iglesia trabajan en ménsula, anclados al terreno y libres en la parte superior; por ello, en su cálculo se han tenido especialmente en cuenta las acciones del viento.
Al igual que el resto de la obra, y con la misma intención, todos los accesorios fijos como: altares, pilas de agua bendita, confesionarios y fuente bautismal son de hormigón armado dejado visto y acabado con martellina a mano.

El pavimento de la iglesia ha sido tratado con mármol travertino.

Las vidrieras y el crucifijo se han realizado, según diseño del proyectista, en vidrio catedral coloreado.

La cerrajeria y las verjas se realizaron con clavos forjados soldados entre si, también según diseño del proyectista.

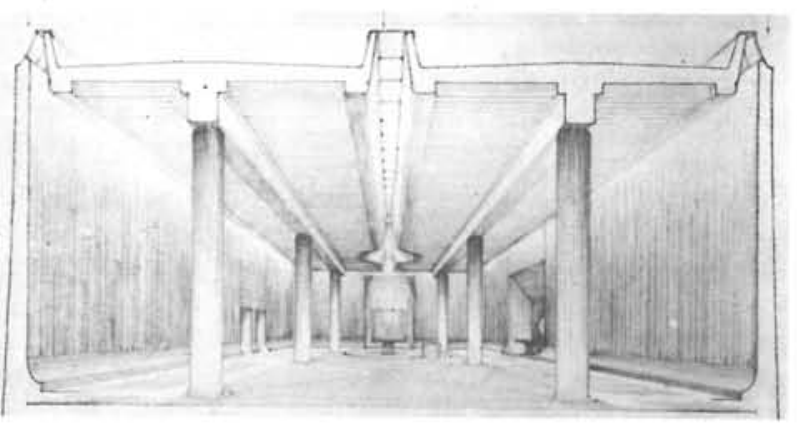

